This item was submitted to Loughborough's Research Repository by the author.

Items in Figshare are protected by copyright, with all rights reserved, unless otherwise indicated.

\title{
Engineering controls for surgical smoke in laser medical handpieces
}

PLEASE CITE THE PUBLISHED VERSION

https://doi.org/10.2351/7.0000360

PUBLISHER

AIP

VERSION

AM (Accepted Manuscript)

PUBLISHER STATEMENT

This article may be downloaded for personal use only. Any other use requires prior permission of the author and AIP Publishing. This article appeared in Journal of Laser Applications 33, 022007 (2021) and may be found at https://doi.org/10.2351/7.0000360.

\section{LICENCE}

All Rights Reserved

\section{REPOSITORY RECORD}

Jones, Lewis, Mark Parry, Jason Britton, and John Tyrer. 2021. "Engineering Controls for Surgical Smoke in Laser Medical Handpieces”. Loughborough University. https://hdl.handle.net/2134/14095691.v1. 


\section{ENGINEERING CONTROLS FOR SURGICAL SMOKE IN LASER MEDICAL HANDPIECES}

Lewis C. R. Jones ${ }^{1}$, Mark Parry ${ }^{1}$, Jason Britton ${ }^{2} \&$ John R. Tyrer ${ }^{1}$

${ }^{1}$ Wolfson School of Mechanical, Electrical and Manufacturing Engineering, Loughborough University,

Loughborough, Leicestershire, LE11 3TU, UK

${ }^{2}$ Department of Medical Physics, Leeds Teaching Hospitals NHS Trust, Leeds, UK

Corresponding author. Dr Lewis Jones, Wolfson School of Mechanical, Electrical and Manufacturing Engineering, Loughborough University, Loughborough, Leicestershire, LE11 3TU, UK. Email: L.Jones@lboro.ac.uk

\section{ORCID}

Lewis C.R. Jones: 0000-0002-6413-4599

Mark Parry: 0000-0002-7966-3944

Jason Britton: 0000-0002-3145-9274

John Tyrer: 0000-0002-0003-9496

\section{CONFLICT OF INTEREST STATEMENT}

The authors have stated explicitly that there are no conflicts of interest in connection with this article. No funding was received for this work. 


\section{ABSTRACT}

The hazard of surgical smoke is often overlooked when considering the safety of medical laser procedures but can present a high level of occupational risk. Administrative procedures for operating external extraction devices and the reliance on personal protective equipment are not sufficient for reducing the risk. This paper aims to quantify the hazard of laser-generated surgical smoke and demonstrate how effective engineering control solutions can reduce the risk. A new design solution is presented with engineering controls for surgical smoke extraction and optical radiation integrated into the laser handpiece. A fibre delivered diode laser is used to simulate laser vaporisation procedures on porcine skin tissue. Conventional external extraction conditions are compared to the new design solution. Fine particulate mass concentrations (PM2.5) from the simulated procedures, under different extraction conditions, are measured using optical particle size measurements. Peak concentrations of $55.86 \pm 2.79 \mu \mathrm{g} / \mathrm{m}^{3}$ were measured without extraction; showing the hazard of laser-generated surgical smoke is five times greater than the World Health Organisation guideline of $10 \mu \mathrm{g} / \mathrm{m}^{3}$. A typical medical extraction setup only achieved a $16 \%$ reduction in peak concentration values, $47.07 \pm 2.35 \mu \mathrm{g} / \mathrm{m}^{3}$; demonstrating that conventional, external, methods of extraction are ineffective. The new solution was able to capture all particulate material, reducing particulate concentrations to background levels, $2.19 \pm 0.68 \mu \mathrm{g} / \mathrm{m}^{3}$, safely below the current recommended guidelines. The design and results present evidence that it is not only more effective to use engineering control methods but that it is practicable to do so.

KEYWORDS: Laser Safety, PPE, Laser Plume, Laser Condensate, Safety Engineering

\section{INTRODUCTION}

Laser-material interactions in surgical, medical and cosmetic procedures generate unique hazards through surgical smoke (laser-generated plume), and these risks are not adequately understood or controlled [1]-[3]. Previous significant reviews of surgical smoke [4]-[10] have identified potential risks to staff in the environment. These include, but are not limited to, respiratory irritation, the transmission of infectious and cancer cells, and genotoxicity. Reported cases suggest laser-generated surgical smoke caused infection in a surgeon [11] and a nurse [12]. However, the acute and long-term risk to staff of surgical smoke is still unproven [3], but should be treated with caution.

It has, however, been observed that infectious materials can be present in laser plumes [13], and pathologic longterm effects have been demonstrated in rats [14]. One gram of laser-generated surgical smoke contains $40 \mathrm{mg}$ of smoke condensates, with an equivalent mutagenic potential of 3 cigarettes [15].

Based on the assumption that there is a potential risk from laser-generated surgical smoke, and that exposure should be reduced, this paper aims to quantify the hazard of laser-generated surgical smoke and demonstrate how effective engineering control solutions can reduce these risks.

\section{CURRENT PRACTICE IN RISK CONTROL OF LASER GENERATED PLUME}

In the USA, only the state of Rhode Island has effective, from January $1^{\text {st }} 2019$, legislation (RI Gen L $§ 23-17$ 49.1 2018) requiring action for surgical smoke. It is worth noting that Colorado has passed legislation (Colo. Rev. Stat. $\S 25-3-120$ 2019) that will become effective May $1^{\text {st }} 2021$, and the states of New Jersey, Oregon, Utah, Kentucky, Georgia, and Tennessee have bills under various stages of review. However, the Occupational Safety and Health Administration (OSHA) do not provide specific standards for laser/electrosurgery plume hazards [1]. In the UK, there is no specific legal requirement for surgical departments to use smoke extraction systems [2]. Yet, both countries do have general legislation that requires employers to protect their employees from harm. This legislative situation results in a variety of practices and non-regulatory guidance in how surgical smoke should be controlled. 
The recommendations from research on risk control for surgical smoke includes the use of Local Exhaust Ventilation (LEV) and Personal Protective Equipment (PPE) [4]-[7], [10], [16]-[18]. Incorrect use is a major issue and improved education and training are recommended [7]. USA guidance includes reports from the National Institute for Occupational Safety and Health (NIOSH) to use LEV. UK guidance includes recommendations from the Medical and Healthcare Products Regulatory Agency (MHRA) to use masks and LEV [19] to meet the Control of Substances Hazardous to Health Regulations (COSHH) (SI 2002/2677) requirements. There are, however, serious issues that occur with LEV and PPE in practice.

LEV should be mandatory in conjunction with cosmetic laser procedures [9] as it is effective in reducing the risk to humans of air contaminants [20]. The problem with this is that while an LEV system appears to be a suitable control method, it is highly reliant on the operator, policies and administrative procedures [7], [21]. This is because in a typical laser treatment system, the laser delivery handpiece (FIG. 1a) is separate from extraction nozzle and LEV (FIG. 1b). The extraction nozzle or smoke extraction pencil used to capture the surgical smoke is sensitive to position to effectively collect laser-generated airborne contaminants [22]. Since the extraction is often manually operated by a different user to the laser, it is highly unlikely that adequate extraction conditions can be maintained. Research has reported that LEV was only used in $47 \%(\mathrm{n}=1315)$ of laser surgeries, and $31 \%$ of procedures never used LEV [9]. Hill, O’Neill, Powell, and Oliver [16] reported that only 66\% $(n=50)$ of plastic surgery theatres had specialised smoke extractors. Spearman, Tsavellas, and Nichols [23] reported that only 43\% $(n=67)$ of surgical consultants used smoke evacuators. It appears that even when LEVs are available, they are not routinely used. Interference, acoustic noise, cumbersome equipment and lack of perceived risk are cited as reasons for non-use [21]. While education can improve compliance with smoke evacuation system use [24], it does not ensure its correct use. This issue of human noncompliance has been previously identified, but no clear control solution has arised [8, p. 465].

FIG. 1. Example of a typical medical laser system showing the separate a) handpiece and b) local exhaust extraction systems used during laser procedures.

Surgical face masks do not provide measurable protection from surgical smoke; therefore, N95 or Filtering Facepiece (FFP) respirators are the commonly used solution to surgical smoke [25], [26]. The use of masks has two key issues. Firstly, masks are not completely effective at filtering any smoke that has not been captured by the LEV. This issue is often associated with poor fit and seal of masks [6], [26]. Secondly, the use of PPE as a primary method of risk reduction [5], [27], is a serious breach of health and safety practices. Under UK law, PPE can only be used in situations where hazard risk cannot be controlled by other means.

A new technical control solution for laser-generated surgical smoke is required [28] to replace or supplement the existing methods that are not suitable for practical, technical and legal reasons.

\section{DESIGN OF AN INHERENTLY SAFE LASER HANDPIECE}

The international method (ANSI / ISO 12100:2012) for the design of any safe machinery is the hierarchy of control measures. This prioritises the use of inherently safe design measures through engineering controls over administrative/informative and PPE as methods for risk reduction. The application of this hierarchy to laser procedures is shown in TABLE I, and the risk control measures must be implemented in the order specified. 
TABLE I. Hierarchy of control measures for laser-generated surgical smoke

\begin{tabular}{ll}
\hline Risk control & Implementation in laser procedures \\
\hline $\begin{array}{l}\text { 2. Elimination } \\
\text { 3. Engstitution }\end{array}$ & $\begin{array}{l}\text { The first two methods of control are not appropriate. This paper does not question the } \\
\text { medical reasoning for using a laser procedure or the efficacy of such procedures. } \\
\text { Therefore, the source of the smoke generation cannot be eliminated or substituted. }\end{array}$ \\
& $\begin{array}{l}\text { This is the first level of control that should be implemented. Current systems do not } \\
\text { achieve this due to reliance on human activation and manoeuvring of LEV. The smoke } \\
\text { extraction system should be interlocked to the activation of the procedure so that it is } \\
\text { always active when required. It should also address the hazard at the point of generation. }\end{array}$ \\
4. Administrative controls & $\begin{array}{l}\text { Current methods rely significantly on policies and procedures being followed. The } \\
\text { efficacy of the LEV system is entirely reliant on the operator holding the extraction } \\
\text { system. This is a fundamental failure mode of the current risk control system. } \\
\text { PPE will be worn in medical and surgical environments as it is recognised that there are } \\
\text { clothing and equipment }\end{array}$ \\
$\begin{array}{l}\text { additional risks from infectious bodily fluid splashes. This aspect of the PPE is not under } \\
\text { question. Face masks, however, should not be the primary method of risk reduction for } \\
\text { surgical smoke. }\end{array}$
\end{tabular}

The primary design consideration for an inherently safe laser handpiece is the engineering control of the lasergenerated surgical smoke but it must also consider the radiation hazard. A prototype solution to controlling the risk of the identified hazards is shown in FIG. 2. This design provides the following functionality:

- $\quad$ The tip of the device is placed in contact with the skin to seal the treatment area and entrap all generated plume. This will maintain the functionality of a standoff gauge for focusing the laser.

- $\quad$ Air is supplied co-axially to the laser beam, providing cooling to the treatment zone and providing positive airflow to move the fume away from the point of generation. An external annular ring encases the source of the plume, ensuring that extraction is provided locally and in all directions. This assists extraction and prevents debris from damaging the fibre while improving visibility. Air pressure is balanced between the inlet, extraction area, and outlet to provide the necessary extraction without suction onto the skin.

- Integrated extraction in the handpiece ensures that the extraction system is always located at the point of fume generation. Capturing the fume at source removes the need for PPE as the primary control method to manage the fume risk.

- $\quad$ The laser and extraction operation are interlocked to a sensor used to detect skin contact which is required for a Class 1C (IEC 60825-1:2014) device [29]. Interlocking will prevent operation of the laser without a seal to the skin and active extraction. Therefore, removing user error for non-compliance with fume extraction and preventing accidental direct and indirect optical radiation exposure to persons around the patient.

- Improved process monitoring with an integrated endoscopic camera. This enables directed targeting of the treatment zone and live process monitoring without the risk of eye injury.

FIG. 2. Integrated Handpiece Extraction schematic showing device features and airflow path

The following sections will quantify how the integrated extraction handpiece can control laser-generated particulate.

\section{METHOD}

To provide evidence for the risk of laser fume and to evaluate how the engineering controls of the proposed inherently safe design can reduce the risk to patient and staff during laser procedures the experimental set up in FIG. 3 
was used. The entire experimental assembly was located within a sealed Class 1 (IEC 60825-1:2014), a cube of length $1220 \mathrm{~mm}$, enclosure to prevent any accidental laser radiation exposure and to reduce any external air movement effects. This was used to evaluate the composition and extraction of laser-generated surgical smoke under the following test conditions: Surgical smoke characterisation; Effect of conventional extraction methods on surgical smoke concentration; Effect of inherently safe handpiece extraction method on surgical smoke concentration.

FIG. 3. Experimental schematic for laser fume generation, capture, and measurement.

A Biolitec diode laser $(\lambda=810 \mathrm{~nm}$, maximum power $=20 \mathrm{~W}, 600 \mu \mathrm{m}$ fibre delivery $)$ was used to generate results for this medical procedure simulation. Previous works have shown that there is not a significant difference in the plume produced by different laser sources for similar treatments [30], [31], and so the authors expect this investigation to be transferrable in some respect to other lasers sources. The laser was programmed to perform a $23 \mathrm{~s}$ sequence of laser pulses to produce surgical smoke and simulate a procedure. In total 6 pulses, power of $14 \mathrm{~W}$, were delivered to the surface with a pulse length of $3 \mathrm{~s}$ and a delay of 1 second between pulses.

The simulated laser procedures were performed on porcine skin as it is accepted as one of the most practical substitutes for human skin [32]. This was chosen specifically for this study due to the similarity of epidermal thickness, lipid construction, and sparse hair coat between human and porcine skin tissue [33], [34]. Stationary tissue samples were placed under the laser, and the laser was targeted at a fresh location of the skin for each test.

Two extraction methods are used to assess the difference between conventional External Extraction systems and the Integrated Handpiece Extraction. The laboratory extraction system was used to simulate the effect of medical LEV systems. Guidance for surgical smoke extraction is a face velocity of 100 to $150 \mathrm{ft} / \mathrm{min}$ [22]. The External Extraction nozzle $(\varnothing 65 \mathrm{~mm})$ was positioned at the same height as the skin at a distance of $150 \mathrm{~mm}$ from the sample. Three values of extraction were used to test the effectiveness of an external extraction source. This was measured using a digital vane anemometer; the measured face velocities and flow rate conversions are shown in TABLE II.

TABLE II. Extraction face velocity and volumetric flow rate used in testing

\begin{tabular}{llll}
\hline $\begin{array}{l}\text { External Extraction } \\
\text { Condition }\end{array}$ & $\begin{array}{l}\text { Face Velocity } \\
\text { Measurement }(\mathrm{m} / \mathrm{s})\end{array}$ & $\begin{array}{l}\text { Volumetric Flow } \\
\text { Rate }(\mathrm{L} / \mathrm{min})\end{array}$ & $\begin{array}{l}\text { Face Velocity } \\
\text { Conversion }(\mathrm{ft} / \mathrm{min})\end{array}$ \\
\hline Low & 2.1 & 419 & 414 \\
Medium & 5 & 996 & 985 \\
High & 13.2 & 2629 & 2599
\end{tabular}

The Integrated Extraction handpiece could be removed and replaced from the stationary fibre support to take particulate measurements with and without the new device. The airflow in and Integrated Handpiece Extraction out was operated at its design specification of $10 \mathrm{~L} / \mathrm{min}$.

Plume characterisation and measurements were performed using a TSI 3330 optical particle sizer spectrometer. Samples are taken at a controlled volumetric air flow rate, Q, of $1.0 \mathrm{~L} / \mathrm{min}( \pm 5 \%)$ inwards. A total collection period of 180s was used for each test. At 40 seconds into each test the laser sequence was started, this was to establish a clear background reading for each test to prevent contamination from other sources and to allow all laser safety features to be activated. Sixteen collection channels ( $n=1$ to 16 ) were used on the device, see FIG. 4 . The values from channels $1-10$ were used in the analysis as these contained particulates with a diameter less than $2.5 \mu \mathrm{m}$ (PM2.5). The sample length, t, was 1 second. To compare the data to other research and acceptable limits, the number of counted particles must be converted to a particulate mass concentration. The raw data was analysed by conversion from counts per channel, c, to a mass concentration, $\gamma_{\mathrm{i}}$ using: 


$$
\sum_{n=1}^{10} \gamma_{n}=\frac{\rho \pi D_{n}^{3} c_{n}}{6 t Q}
$$

Where $D_{n}$ is the mean particle diameter per channel, where the particles are assumed to be spherical, and $\rho$ is the average density of the particulate matter. A density value of $1.2 \mathrm{~g} / \mathrm{cm}^{3}$ was used in this work as a suitable estimate for organic aerosol density for PM2.5 [35]. The validity of the density values used and the presentation of PM2.5 concentration data are discussed in the analysis of results.

\section{RESULTS}

Characterisation of the particulate distribution, from all measurement channels, generated by the laser treatment is shown in FIG. 4. To generate this data, the total particles collected in each channel during the background measurement were subtracted from a porcine test without the use of any extraction method. The threshold for the channels used for the PM2.5 measurement is shown. This represents $99.8 \%$ of the total particles collected, making it a viable method for analysis for this work. The data for particulates in channels greater than $2.5 \mu \mathrm{m}$ are not considered in this paper due to the insignificant data collected in this range. A normal distribution of the particles is displayed, which identifies a peak particle diameter in the distribution between 0.374 and $0.579 \mu \mathrm{m}$. The authors would expect particulate in the $<\varnothing 300 \mathrm{~nm}$ range to be present, as other analyses of surgical smoke have shown peak particulate counts with diameters of $145 \mathrm{~nm}$ [25] and $7 \mathrm{~nm}$ [36]. However, these results are outside of the measurement capability of this study.

FIG. 4. Particle size distribution analysis of porcine skin sample with removal of background reading and no extraction.

The concentration of PM2.5 is a useful method for analysis of hazardous aerosols and airborne particulates and has previously been used to analyse surgical smoke [37]-[39]. The fine particulates measured by PM2.5 are associated to an increase in daily mortality [40], [41] and linked to pulmonary diseases [17], [18]. The World Health Organisation (WHO) annual mean exposure guidelines for PM2.5 is $10 \mu \mathrm{g} / \mathrm{m}^{3}$ [42]. This value is used in this analysis as the threshold to consider the particulate concentrate safe for long-term exposure for staff.

The time response for particulate generated by the laser process is shown in FIG. 5. The background particulate mass concentration had a mean of $1.29 \mu \mathrm{g} / \mathrm{m}^{3}$ with a standard deviation of $0.66 \mu \mathrm{g} / \mathrm{m}^{3}$. This is significantly below the WHO guideline level and is lower than the typical background measurement for the United States and Western Europe. This shows that the background level is low, and the enclosure used for the experiment is sufficient to prevent other sources of contamination.

The pre-sample collection time was used to check that there was no external contamination prior to each test. Although there were statistically significant differences in the mean concentrations for the pre-sample collection times, $\mathrm{F}(5,234)=28.222, \mathrm{p}=.000$, the mean concentrations for each of the pre-sample collection times are all less than 3 $\mu \mathrm{g} / \mathrm{m}^{3}$. Therefore, all the tests were unaffected by the natural variation in background particulate concentration, and to aid the presentation of data the pre-sample collation times have been removed from subsequent plots.

FIG. 5. Comparison of background particulate concentration levels to laser testing without extraction

There is a clear response between the laser process and the PM2.5 concentration levels. There is a 12s delay between the start of the laser sequence and the measured rise in particulate concentration. This is likely due to the offset distance between the source of particulates and the measurement instrument. There is a peak measurement of $55.86 \pm$ $2.79 \mu \mathrm{g} / \mathrm{m}^{3}$. This equals a 43 times increase in the PM2.5 concentration as a result of a single treatment area of the laser. 
Another effect of this process is the further delayed response to an increase in PM2.5 concentration after the process has completed. As there is no extraction present, from approximately 40 seconds after the laser process, there is a significant increase in the concentration; this is suspected to occur as the uncollected particulate spreads in the enclosed environment. The last 60 seconds of measurement has a mean concentration of $13.04 \mu \mathrm{g} / \mathrm{m}^{3}$ with a standard deviation of $2.86 \mu \mathrm{g} / \mathrm{m}^{3}$, a level which is now above the recommended guidelines. This shows that there is a significant risk from the use of laser procedure without extraction devices and provides an upper limit of the particulate generation that we expect to measure in this study.

The effect of the external extraction device on surgical smoke removal is analysed in FIG. 6. This compared the three different levels of extraction. Extraction levels 419 and $996 \mathrm{~L} / \mathrm{min}$ had peak PM2.5 concentrations of $47.07 \pm 2.35$ $\mu \mathrm{g} / \mathrm{m}^{3}$ and $11.71 \pm 0.59 \mu \mathrm{g} / \mathrm{m}^{3}$, respectively. Both extraction levels exceed the WHO PM2.5 annual mean guideline values and therefore were ineffective at maintaining a safe level of surgical smoke exposure. The highest level of extraction, $2629 \mathrm{~L} / \mathrm{min}$, was able to keep the level below the guideline.

FIG. 6. The effectiveness of external extraction systems on particulate concentrations

The concentrations observed without and with external extraction devices in FIG. 5 and FIG. 6, respectively are in alignment with the research of Tan et al. [37] who measured PM2.5 concentrations of $46.89 \pm 20.39 \mu \mathrm{g} / \mathrm{m}^{3}$ in adipose tissue. Similarly, Tanpowpong \& Koytong [38] reported pre-laser concentration of $69.0 \pm 13.4 \mu \mathrm{g} / \mathrm{m}^{3}$, and during-laser concentrations of $111.0 \pm 13.0 \mu \mathrm{g} / \mathrm{m}^{3}$ in the operative room. This suggests that concentration values are in the same range as other studies near the surgical site.

The key finding of this paper, FIG. 7, is the difference in PM2.5 concentration next to the treatment area using a conventional external extraction nozzle and an integrated handpiece extraction. The conventional extraction system repeatedly exceeds the WHO PM2.5 annual mean guideline value of $10 \mu \mathrm{g} / \mathrm{m}^{3}$ while there is no measured effect of surgical smoke when the integrated handpiece extract device is used.

FIG. 7. Demonstration of complete particulate removal using integrated handpiece extraction

The difference between the mean concentration with the integrated extraction device and the background measurement is $0.9 \mu \mathrm{g} / \mathrm{m}^{3}$, which indicates only a small deviation from the pre-testing measurement. At no point does the PM2.5 concentration exceed the WHO PM2.5 annual mean guidelines with the integrated handpiece extraction.

\section{DISCUSSION}

\section{Hazards of Surgical Smoke}

The key finding of the results has shown that an Integrated Handpiece Extraction is significantly more effective at surgical smoke extraction than the use of external extraction methods. No PM2.5 particles were measured to have escaped from the Integrated Handpiece Extraction device.

When using the lowest level of extraction in this study, there is only a 16\% decrease in the PM2.5 peak concentration value compared to no extraction. While a volumetric flow rate of $419 \mathrm{~L} / \mathrm{min}$ was the lowest level of extraction in this study, it is important to note that the $2.1 \mathrm{~m} / \mathrm{s}$ face velocity used to generate this is more than four times the recommended face velocity of a surgical extraction system [22]. Peak PM2.5 concentrations exceeding the WHO guidelines were still measured at extraction rates of $996 \mathrm{~L} / \mathrm{min}$, more than nine times the recommendation. This demonstrates that even when external extraction systems are used, it is possible for a large percentage of surgical smoke generated not to be captured by the system. The testing performed in this analysis was also only for a single laser sequence totalling $23 \mathrm{~s}$ of smoke generation. Whereas in real use, the operator would be continuously generating smoke during treatment of multiple patients per day. 
Another consequence of using the Integrated Handpiece Extraction is that it is capable of full smoke extraction at a considerably reduced volumetric flow rate, using only $10 \mathrm{~L} / \mathrm{min}$. This will help with the negative environmental factors often quoted as the reason for non-compliance with LEVs [21], as a reduced extraction requirement can be smaller and produce less noise.

The method of analysis used in this study, PM2.5, only identifies the respirable hazard associated to particles with a fine aerodynamic diameter. However, in a real-world situation, surgical smoke has a unique toxicology and risk of infection through airborne particulates which provides additional occupational hazards to workers [11], [13], [15], [31], [43]. The COVID 19 pandemic has highlighted the increased risk from aerosols to healthcare workers, and that PPE is not completely effective at controlling hazards form aerosol-generating procedures [44]-[46]. This supports a combined strategy of protection utilising engineering controls where they are practicable.

\section{Limitations of the method}

The most significant limitation to this study is the estimation of PM2.5 mass concentration from the particulate count, as this is reliant on the assumption of average particle density. This study used a density value of $1.2 \mathrm{~g} / \mathrm{cm}^{3}$ to estimate the surface of the skin. However, it has been shown that the particle concentration of surgical smoke produced by electrosurgery of different human tissues varies [36]. An analysis of density sensitivity, low (equivalent to water: 1 $\mathrm{g} / \mathrm{cm}^{3}$ ) and high (double the estimate: $2.4 \mathrm{~g} / \mathrm{cm}^{3}$ ) value estimates are used to demonstrate the effect on the results, TABLE III. Even with a low estimate of average particle density, when using the External Extraction device, there are still measurements above the WHO PM2.5 annual mean exposure guidelines. Using a higher estimation of density shows that, as expected, the hazard conditions are increased, but both Background and Integrated Handpiece Extraction results are still below the guideline limit.

TABLE III Sensitivity analysis of PM2.5 mass concentration calculation to average particle density

\begin{tabular}{|c|c|c|c|c|c|c|}
\hline \multirow[b]{2}{*}{ Extraction Method } & \multicolumn{3}{|c|}{ Density: $1 \mathrm{~g} / \mathrm{cm}^{3}$} & \multicolumn{3}{|c|}{ Density: $2.4 \mathrm{~g} / \mathrm{cm}^{3}$} \\
\hline & Mean & SD & Max & Mean & SD & Max \\
\hline Background & 1.07 & 0.52 & 2.18 & 2.56 & 1.25 & 5.24 \\
\hline External Extraction 419 L/min & 8.52 & $9.60 *$ & $39.23 *$ & $20.44^{*}$ & $23.03 *$ & $94.15^{*}$ \\
\hline Integrated Handpiece Extraction & 1.83 & 0.57 & 3.02 & 4.38 & 1.37 & 7.25 \\
\hline
\end{tabular}

Note: Descriptive statistics are taken from $\mathrm{t}=0$ to $30 \mathrm{~s}$. All values are PM2.5 mass concentration in $\mu \mathrm{g} / \mathrm{m}^{3}$ *Value is above the WHO PM2.5 annual mean exposure guidelines

The method of particulate data collection is more susceptible to undercounting of results due to particle entrapment in collection pipework and if more than one particle enters the detector. The optical particle sizer used in this study has been shown to have good linearity $\left(\mathrm{R}^{2}>0.99\right)$ between measured counts and reference concentrations at values below $1000 \# / \mathrm{cm}^{3}$ [47], which is within the measured values of this study. Therefore, the errors resulting from the chosen method are likely to result in a conservative calculation of the particulate mass concentration generated.

Due to the identified uncertainty in particulate density, the paper recommends that future work on surgical smoke characterisation be conducted into a more accurate density measurement of different tissues from the 0.1 to 10 $\mu \mathrm{m}$ particle diameter range. This would also provide more useful data to the field of environmental pollution and increase understanding of the respirable hazard of these materials.

\section{Design Proposal}


The experimental results have shown that an Integrated Handpiece Extraction system would be capable of containing the generated surgical smoke from laser procedures on the skin. However this experiment does not simulate the complexity of surgical smoke generation in a real medical environment [48], and further work would be required to translate the potential demonstrated in these results to a real medical situation. It would also be necessary to generate feedback from surgeons and perioperative nurses on the practicality of this device. Integrated extraction devices have been shown to be effective in electrosurgery [49] but are easier to implement as there is no optical radiation risk, which can present a hazard with a typical range larger than the room the procedure is performed within. To demonstrate how the tested Integrated Handpiece Extraction device would be incorporated into laser medical handpieces, computer and 3D printed modules are shown in FIG. 8.

The new Integrated Handpiece Extraction replaces existing focus gauges on laser handpieces to combine the focusing function with the extraction at the source of surgical smoke generation. External tubing for the air inlet, extraction outlet and endoscopic camera are shown in FIG. 8b, but to improve functionality for the user, these could be incorporated internally to the handpiece.

FIG. 8. Design proposal for Integrated Handpiece Extraction a) CAD model of system showing assembly. b) 3D printed model to demonstrate design with extraction connection.

When considering the safety of a laser handpiece, the instinctive reaction would be to focus all attention on the high power laser source which dependant on the wavelength of the machine will present a significant hazard to the skin and/or retina of the operator. However, it was the authors' intention in this paper to emphasise the overlooked hazard of surgical smoke generation from these devices. The significant advantage of using an enclosed extraction tip on laser handpieces is that the shroud for the extract can also be used to interlock and contain the laser radiation. This would enable future laser handpieces to meet the modern Class $1 \mathrm{C}$ laser safety product classification for medical devices. The material of the Integrated Handpiece Extraction can be easily chosen to contain the optical radiation, while an endoscope can provide magnified and recordable viewing of the treatment location.

\section{CONCLUSION}

The aim of this paper was to quantify the hazard of laser-generated surgical smoke and demonstrate how effective engineering control solutions can reduce these risks. A discussion on the extant literature relating identified a considerable reason for concern with the hazards associated to laser medical handpieces. Existing work has been reliant on the use of PPE, or manual operation of LEV extraction for and hazard control. There is a strong regulatory requirement to control risks to workers and hazards in products, and the argument that effective engineering controls should be the primary strategy for this risk reduction over PPE has been established.

This paper has provided further evidence for the quantification of laser-generated surgical smoke hazards where the results have shown surgical smoke peak PM2.5 concentrations of $55.86 \pm 2.79 \mu \mathrm{g} / \mathrm{m}^{3}$ when no extraction is present, from the relatively small source of a single laser sequence. This represents an exposure greater than five times the World Health Organisation recommended guidelines. When a typical external extraction system was used, the surgical smoke exposure was only reduced by $16 \%$, to a value of $47.07 \pm 2.35 \mu \mathrm{g} / \mathrm{m}^{3}$. These results demonstrate the hazard from laser surgical smoke and the ineffective nature of manually operated external extraction systems.

A solution for an Integrated Handpiece Extraction system has been presented and evaluated. Testing of the system demonstrated that it could capture all the surgical smoke produced and providing a safe environment for the operator. With the system installed the particulate level in the area was $2.19 \pm 0.68 \mu \mathrm{g} / \mathrm{m}^{3}$; which is similar to the average background measurement of the test environment and below the guideline values. The analysis has identified that when not using a complete smoke capture system such as the Integrated Handpiece Extractor, conventional 
External Extraction systems release PM2.5 concentrations of $44.88 \pm 2.45 \mu \mathrm{g} / \mathrm{m}^{3}$ above background measurements, which is approximately 4.5 times the recommended limit.

Important benefits of this approach are not only the capture of all surgical smoke generated. Engineering controls prevent extraction devices from being misused, turned off, or forgotten. As the proposed interlocked design would ensure the device is always activated when the laser is in use, it is a method for the elimination of key failure points in existing control system solutions. This design would assist in legal compliance following standard machinery and product safety guidance. The authors conclude that it is feasible and therefore reasonably practicable to utilise engineering controls, rather than administrative and PPE, for risk reduction in laser-generated surgical smoke. But it is also critical that further work in improved safety control does not affect the medical efficacy of the procedure.

\section{ACKNOWLEDGEMENTS}

Thanks to Laser Optical Engineering Ltd and Leeds Teaching Hospitals NHS Trust for access to equipment used in the project. The authors would also like to thank Jack Edwards and Matthew Jones for their contribution to preliminary work for this manuscript.

\section{REFERENCES}

[1] Occupational Safety and Health Administration, "Laser/Electrosurgery Plume." https://www.osha.gov/SLTC/laserelectrosurgeryplume/ (accessed Jul. 23, 2020).

[2] A. J. Beswick and G. Evans, "RR922 - Evidence for exposure and harmful effects of diathermy plumes (surgical smoke),” 2012. Accessed: Mar. 20, 2019. [Online]. Available: www.nationalarchives.gov.uk/doc/open-government-licence/,.

[3] N. Mowbray, J. Ansell, N. Warren, P. Wall, and J. Torkington, "Is surgical smoke harmful to theater staff? a systematic review," Surg. Endosc., vol. 27, no. 9, pp. 3100-3107, Sep. 2013, doi: 10.1007/s00464-013-2940-5.

[4] W. L. Barrett and S. M. Garber, "Surgical smoke: a review of the literature," Surg. Endosc., vol. 17, no. 6, pp. 979-987, Jun. 2003, doi: 10.1007/s00464-002-8584-5.

[5] J. K.-M. Fan, F. S.-Y. Chan, and K.-M. Chu, "Surgical Smoke," Asian J. Surg., vol. 32, no. 4, pp. 253-257, Oct. 2009, doi: 10.1016/S1015-9584(09)60403-6.

[6] E. Alp, D. Bijl, R. P. Bleichrodt, B. Hansson, and A. Voss, "Surgical smoke and infection control," J. Hosp. Infect., vol. 62, no. 1, pp. 1-5, Jan. 2006, doi: 10.1016/j.jhin.2005.01.014.

[7] E. Tan and K. P. Russell, "Surgical plume and its implications: A review of the risk and barriers to a safe work place,” J. Perioper. Nurs., vol. 30, no. 4, pp. 33-39, 2017, doi: 10.26550/2209-1092.1019.

[8] J. S. Pierce, S. E. Lacey, J. F. Lippert, R. Lopez, and J. E. Franke, “Laser-Generated Air Contaminants from Medical Laser Applications: A State-of-the-Science Review of Exposure Characterization, Health Effects, and Control,” J. Occup. Environ. Hyg., vol. 8, no. 7, pp. 447-466, Jul. 2011, doi: 10.1080/15459624.2011.585888.

[9] A. L. Steege, J. M. Boiano, and M. H. Sweeney, "Secondhand smoke in the operating room? Precautionary practices lacking for surgical smoke,” Am. J. Ind. Med., vol. 59, no. 11, pp. 1020-1031, 2016, doi: 
10.1002/ajim.22614.

[10] B. C. Ulmer, “The Hazards of Surgical Smoke,” AORN J., vol. 87, no. 4, pp. 721-738, Apr. 2008, doi: 10.1016/j.aorn.2007.10.012.

[11] P. Hallmo and O. Naess, "Laryngeal papillomatosis with human papillomavirus DNA contracted by a laser surgeon,” Eur. Arch. Oto-Rhino-Laryngology, vol. 248, no. 7, pp. 425-427, 1991.

[12] L. Calero and T. Brusis, "Laryngeal papillomatosis - first recognition in Germany as an occupational disease in an operating room nurse," Laryngo-Rhino-Otologie, vol. 82, no. 11, pp. 790-793, Nov. 2003, doi: 10.1055/s2003-44546.

[13] W. S. Sawchuk, P. J. Weber, D. R. Lowy, and L. M. Dzubow, "Infectious papillomavirus in the vapor of warts treated with carbon dioxide laser or electrocoagulation: Detection and protection," J. Am. Acad. Dermatol., vol. 21, no. 1, pp. 41-49, Jul. 1989, doi: 10.1016/S0190-9622(89)70146-8.

[14] B. L. Wenig, K. M. Stenson, B. M. Wenig, and D. Tracey, "Effects of plume produced by the Nd:YAG laser and electrocautery on the respiratory system," Lasers in Surgery and Medicine, vol. 13, no. 2. pp. 242-245, 1993, doi: 10.1002/lsm.1900130213.

[15] T. Yoshifumi et al., "Mutagenicity of smoke condensates induced by CO2-laser irradiation and electrocauterization," Mutat. Res. Toxicol., vol. 89, no. 2, pp. 145-149, 1981, doi: https://doi.org/10.1016/01651218(81)90120-8.

[16] D. S. Hill, J. K. O’Neill, R. J. Powell, and D. W. Oliver, "Surgical smoke - A health hazard in the operating theatre: A study to quantify exposure and a survey of the use of smoke extractor systems in UK plastic surgery units,” J. Plast. Reconstr. Aesthetic Surg., vol. 65, no. 7, pp. 911-916, Jul. 2012, doi: 10.1016/j.bjps.2012.02.012.

[17] Y. Liu, Y. Song, X. Hu, L. Yan, and X. Zhu, “Awareness of surgical smoke hazards and enhancement of surgical smoke prevention among the gynecologists," J. Cancer, vol. 10, 2019, doi: 10.7150/jca.31464.

[18] J. M. Lewin, J. A. Brauer, and A. Ostad, "Surgical smoke and the dermatologist," Journal of the American Academy of Dermatology. 2011, doi: 10.1016/j.jaad.2010.11.017.

[19] MHRA, "Lasers, intense light source systems and LEDs - guidance for safe use in medical, surgical, dental and aesthetic practices,” 2015. Accessed: Jul. 04, 2018. [Online]. Available: https://assets.publishing.service.gov.uk/government/uploads/system/uploads/attachment_data/file/474136/Laser _guidance_Oct_2015.pdf.

[20] J. G. Hunter, “Laser smoke evacuator: Effective removal of mutagenic cautery smoke,” Aesthetic Plast. Surg., vol. 20, no. 2, pp. 177-178, 1996, doi: 10.1007/BF02275539.

[21] K. Stanley, "Diathermy smoke shown to be hazardous, so why are we not protecting ourselves?," J. Perioper. 
Pract., vol. 28, no. 6, pp. 145-151, 2018, doi: 10.1177/1750458918767582.

[22] NIOSH, “(HC11) Control of Smoke From Laser/Electric Surgical Procedures,” 1998. doi: 10.1080/104732299303205.

[23] J. Spearman, G. Tsavellas, and P. Nichols, "Current attitudes and practiees towards diathermy smoke," Ann. R. Coll. Surg. Engl., vol. 89, no. 2, pp. 162-165, 2007, doi: 10.1308/003588407X155752.

[24] K. Ball, “Compliance With Surgical Smoke Evacuation Guidelines: Implications for Practice,” AORN J., vol. 92, no. 2, pp. 142-149, Aug. 2010, doi: 10.1016/j.aorn.2010.06.002.

[25] S. Gao, R. H. Koehler, M. Yermakov, and S. A. Grinshpun, "Performance of facepiece respirators and surgical masks against surgical smoke: Simulated workplace protection factor study,” Ann. Occup. Hyg., vol. 60, no. 5, pp. 608-618, 2016, doi: 10.1093/annhyg/mew006.

[26] K. Bree, S. Barnhill, and W. Rundell, “The Dangers of Electrosurgical Smoke to Operating Room Personnel: A Review,” Work. Heal. Saf., vol. 65, no. 11, pp. 517-526, 2017, doi: 10.1177/2165079917691063.

[27] M. J. Taravella et al., "Respirable particles in the excimer laser plume," J. Cataract Refract. Surg., vol. 27, no. 4, pp. 604-607, Apr. 2001, doi: 10.1016/S0886-3350(00)00813-0.

[28] I. V. Limchantra, Y. Fong, and K. A. Melstrom, "Surgical Smoke Exposure in Operating Room Personnel," JAMA Surg., vol. 154, no. 10, p. 960, Oct. 2019, doi: 10.1001/jamasurg.2019.2515.

[29] J. Tyrer, "It is possible to make hand delivered medical / cosmetic laser equipment inherently safe," Int. Laser Saf. Conf., pp. 198-204, 2013, doi: 10.2351/1.5056791.

[30] W. Waesche, H. Albrecht, and G. J. Mueller, "Determination of temperature dependence of the production of volatile organic compounds (VOCs) during the vaporization of tissue using Nd:YAG laser, CO2 laser, and electrosurgery devices," in Laser Interaction with Hard and Soft Tissue II, Jan. 1995, vol. 2323, no. January 1995, pp. 393-399, doi: 10.1117/12.199234.

[31] J. Tyrer, L. C. R. Jones, J. Edwards, A. Beswick, D. Bard, and J. Britton, "Viable pathogen aerosols produced during laser dermatology surgery - A quantified analysis," in International Laser Safety Conference, 2019, vol. 1, p. MP602, doi: 10.2351/1.5118631.

[32] B. Godin and E. Touitou, "Transdermal skin delivery: Predictions for humans from in vivo, ex vivo and animal models," 2007, doi: 10.1016/j.addr.2007.07.004.

[33] N. A. Monteiro-Riviere, "Comparative anatomy, physiology, and biochemistry of mammalian skin," in Dermal and Ocular Toxicology: Fundamentals and Methods, D. W. Hobsen, Ed. Boca Raton, FL: CRC Press, 1991, pp. 3-71.

[34] U. Jacobi et al., "Porcine ear skin: an in vitro model for human skin," Ski. Res. Technol., vol. 13, no. 1, pp. 1924, 2007, doi: 10.1111/j.1600-0846.2006.00179.x. 
[35] B. J. Turpin and H. J. Lim, "Species contributions to pm2.5 mass concentrations: Revisiting common assumptions for estimating organic mass," Aerosol Sci. Technol., vol. 35, no. 1, pp. 602-610, 2001, doi: $10.1080 / 02786820119445$.

[36] M. Karjalainen et al., "The characterization of surgical smoke from various tissues and its implications for occupational safety," PLoS One, vol. 13, no. 4, p. e0195274, Apr. 2018, doi: 10.1371/journal.pone.0195274.

[37] W. Tan et al., "Characterization of the PM2.5 concentration in surgical smoke in different tissues during hemihepatectomy and protective measures," Environ. Toxicol. Pharmacol., vol. 72, Nov. 2019, doi: 10.1016/j.etap.2019.103248.

[38] K. Tanpowpong and W. Koytong, "Suspended Particulate Matter in an Office and Laser Smoke Particles in an Operating Room,” J. Med. Assoc. Thail., vol. 85, no. 1, pp. 53-57, 2002.

[39] M. D. Brace et al., “"The air that we breathe': assessment of laser and electrosurgical dissection devices on operating theater air quality,” J. Otolaryngol. - Head Neck Surg., vol. 43, no. 39, Dec. 2014, doi: 10.1186/s40463-014-0039-1.

[40] J. Schwartz, D. W. Dockery, and L. M. Neas, "Is Daily Mortality Associated Specifically with Fine Particles?," J. Air Waste Manag. Assoc., vol. 46, no. 10, pp. 927-939, 1996, doi: 10.1080/10473289.1996.10467528.

[41] Y. F. Xing, Y. H. Xu, M. H. Shi, and Y. X. Lian, “The impact of PM2.5 on the human respiratory system,” J. Thorac. Dis., vol. 8, no. 1, pp. E69-E74, 2016, doi: 10.3978/j.issn.2072-1439.2016.01.19.

[42] World Health Organisation, "WHO Air quality guidelines for particulate matter, ozone, nitrogen dioxide and sulfur dioxide," 2005.

[43] J. D. Sisler et al., "In vitro toxicological evaluation of surgical smoke from human tissue," J. Occup. Med. Toxicol., vol. 13, no. 1, pp. 1-11, 2018, doi: 10.1186/s12995-018-0193-x.

[44] T. M. Cook, "Personal protective equipment during the coronavirus disease (COVID) 2019 pandemic - a narrative review," Anaesthesia, vol. 75, no. 7, pp. 920-927, 2020, doi: 10.1111/anae.15071.

[45] J. B. T. Herron, A. G. C. Hay-David, A. D. Gilliam, and P. A. Brennan, "Personal protective equipment and Covid 19- a risk to healthcare staff?," Br. J. Oral Maxillofac. Surg., vol. 58, pp. 500-502, 2020, doi: 10.1016/j.bjoms.2020.04.015.

[46] V. Madan, "Resumption of laser/IPL skin services post COVID-19 lockdown—British Medical Laser Association (BMLA) guidance document," Lasers Med. Sci., no. May, pp. 1-10, Jun. 2020, doi: 10.1007/s10103-020-03086-z.

[47] H. Han, A. Sreenath, N. T. Birkeland, and G. J. Chancellor, "Performance of a High Resolution Optical Particle Spectrometer," in European Aerosol Conference 2011, 2011.

[48] N. Liu, N. Filipp, and K. B. Wood, "The utility of local smoke evacuation in reducing surgical smoke exposure 
in spine surgery: a prospective self-controlled study," Spine J., vol. 20, no. 2, pp. 166-173, 2020, doi: 10.1016/j.spinee.2019.09.014.

[49] S. H. Pillinger, L. Delbridge, and D. R. Lewis, "Randomized clinical trial of suction versus standard clearance of the diathermy plume,” Br. J. Surg., vol. 90, no. 9, pp. 1068-1071, 2003, doi: 10.1002/bjs.4214. 
Laser fibre, control, and cryogen umbilical
Handheld extraction nozzle

Local Exhaust Ventilation Unit

Laser handpiece
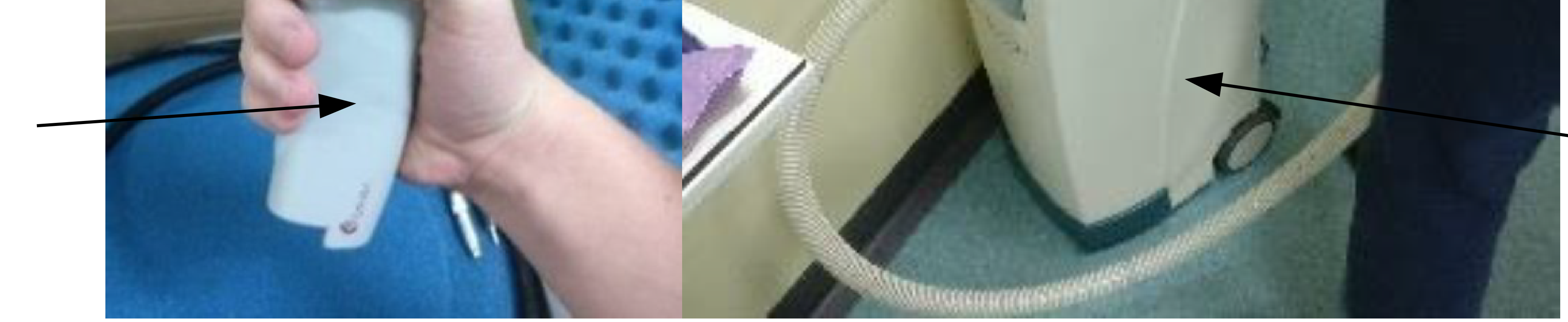
Endoscope camera magnifying target image

Existing laser handpiece body, fibre delivery and focusing optics
Tip seals to skin and makes electrical contact for safety interlock

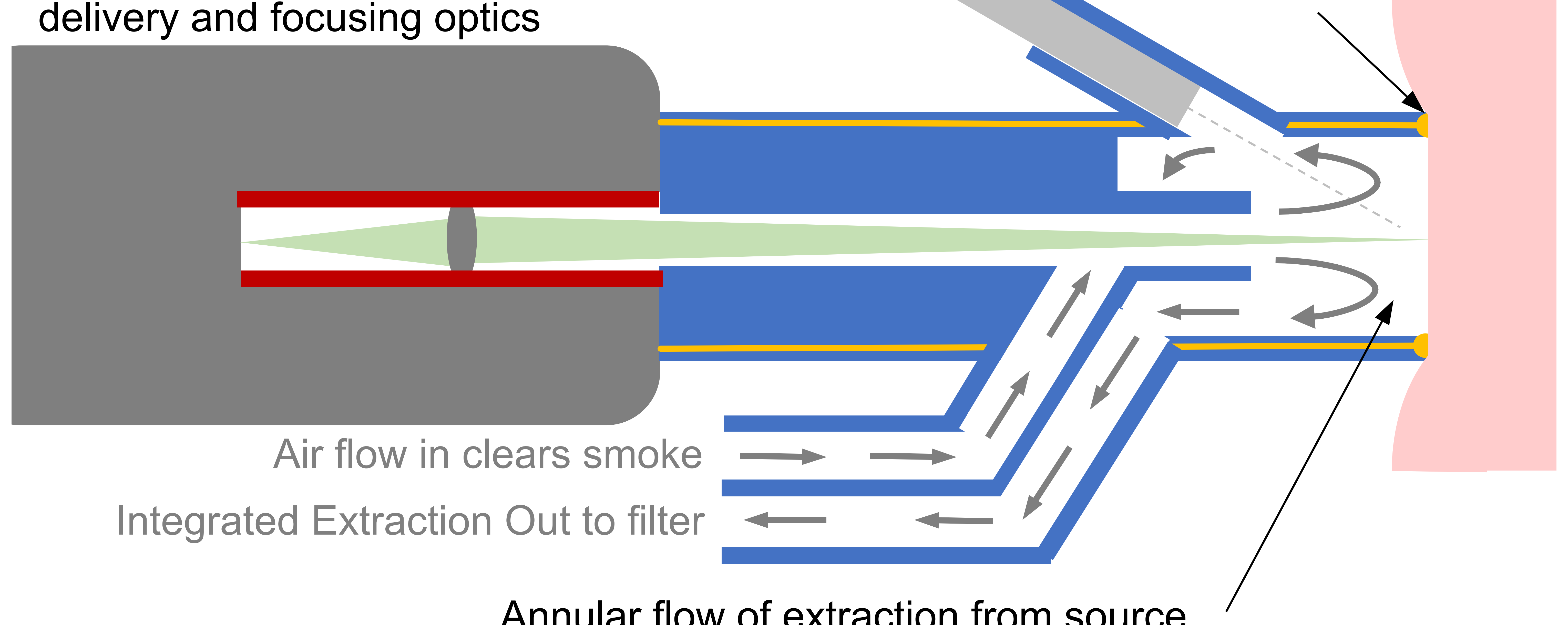

Annular flow of extraction from source 


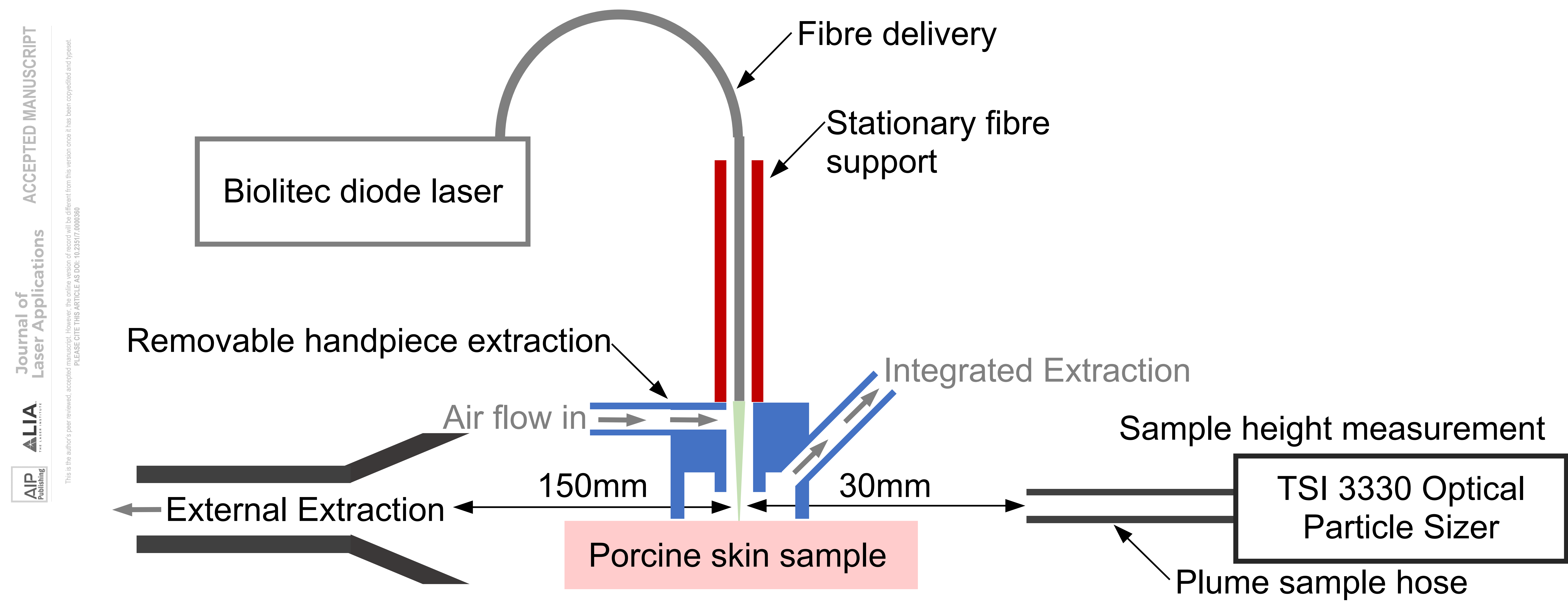




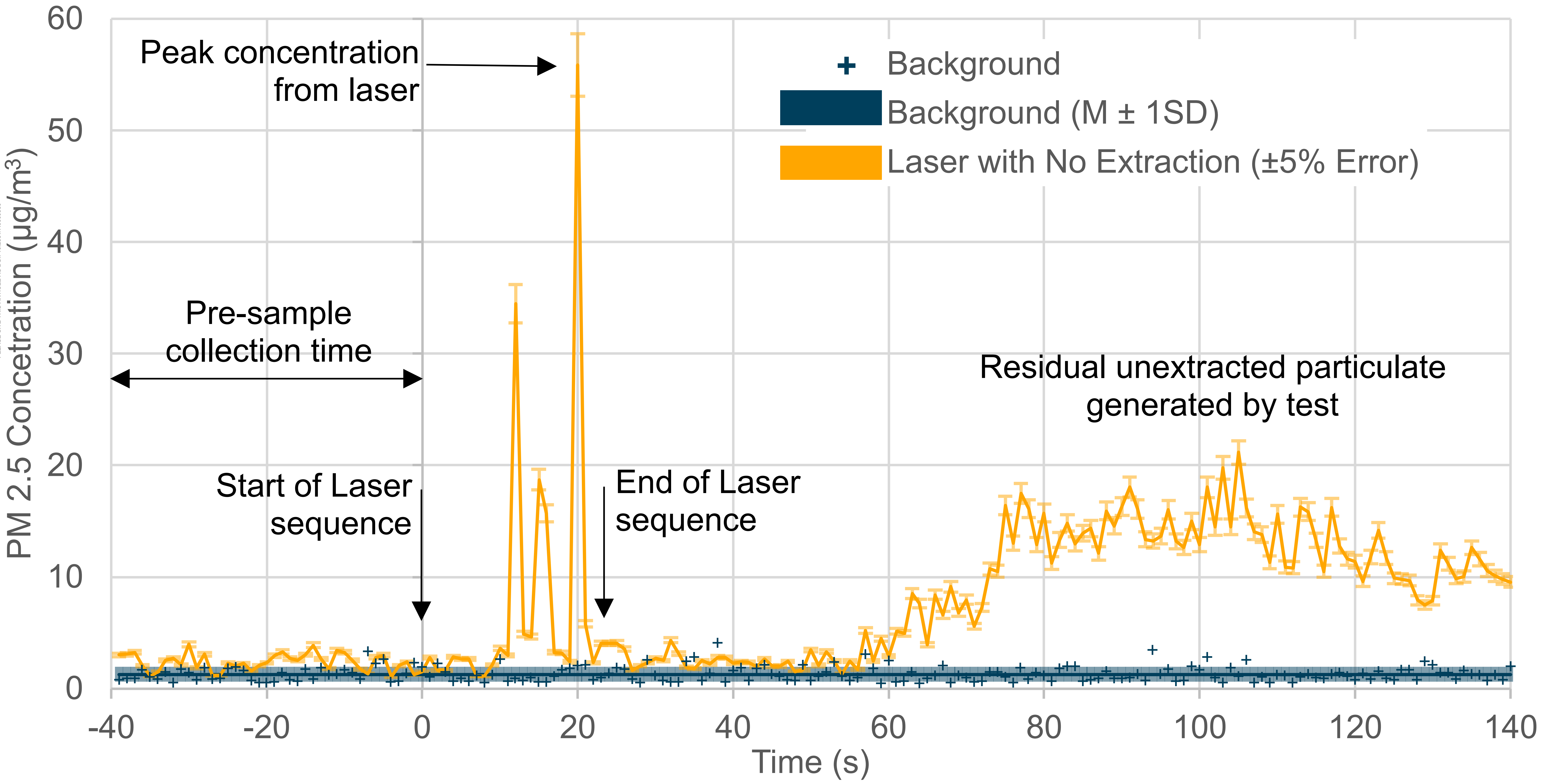




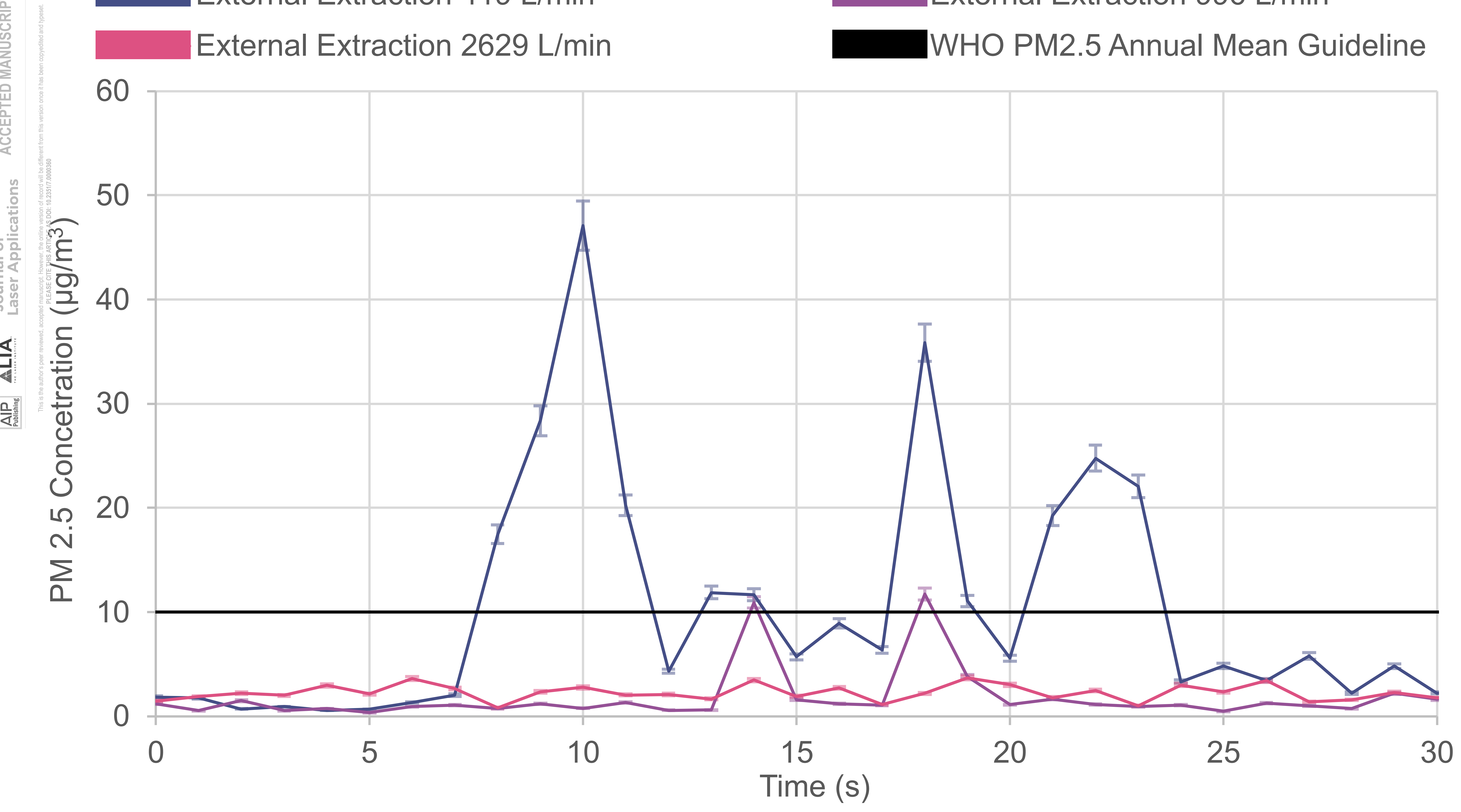




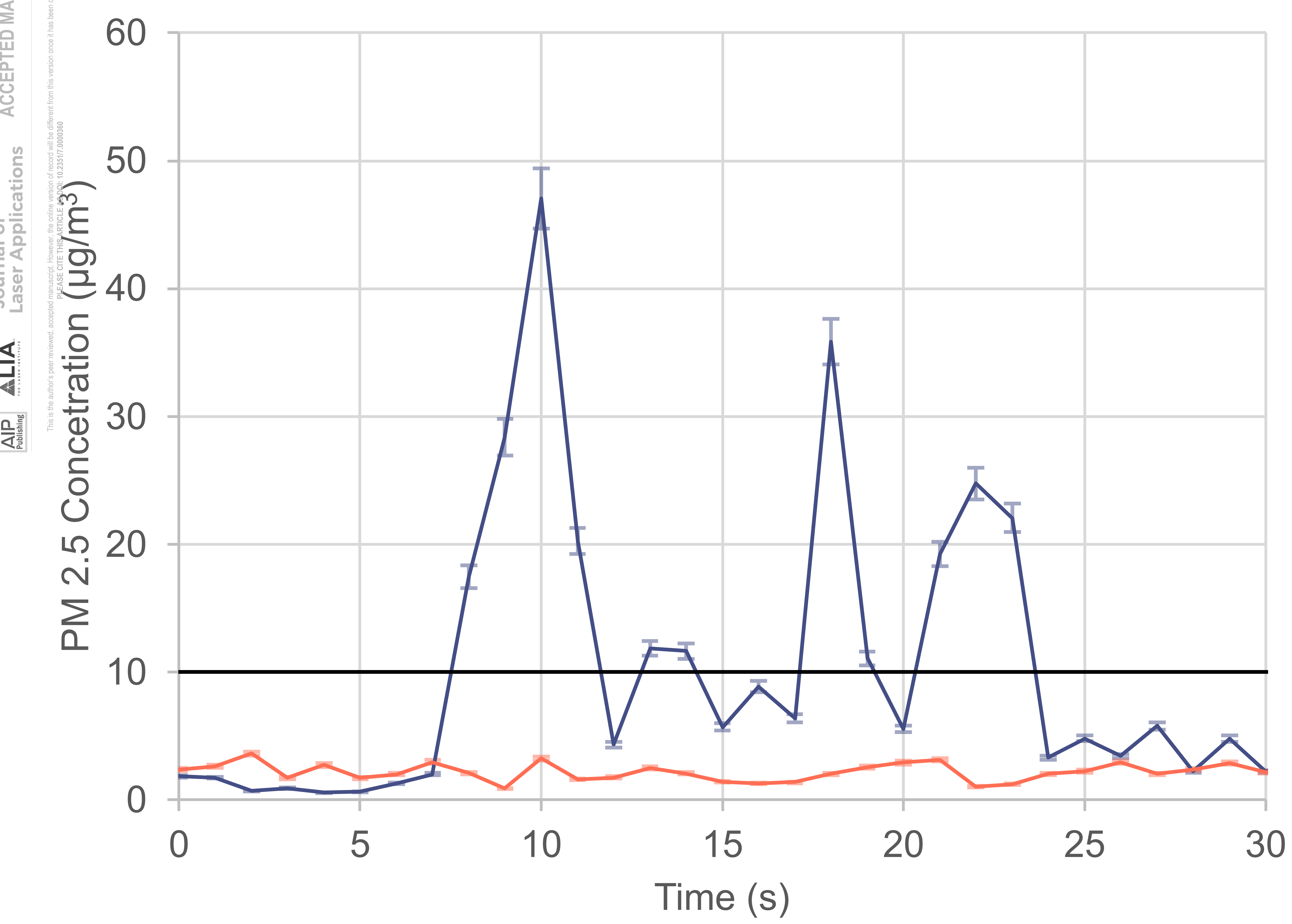

External Extraction $419 \mathrm{l} / \mathrm{min}$ exceeds the WHO PM2.5 annual mean guidance

Integrated Handpiece Extraction shows only room background measurment 
a)

) Air in and Extraction Out

Unaltered handpiece body of existing system b)

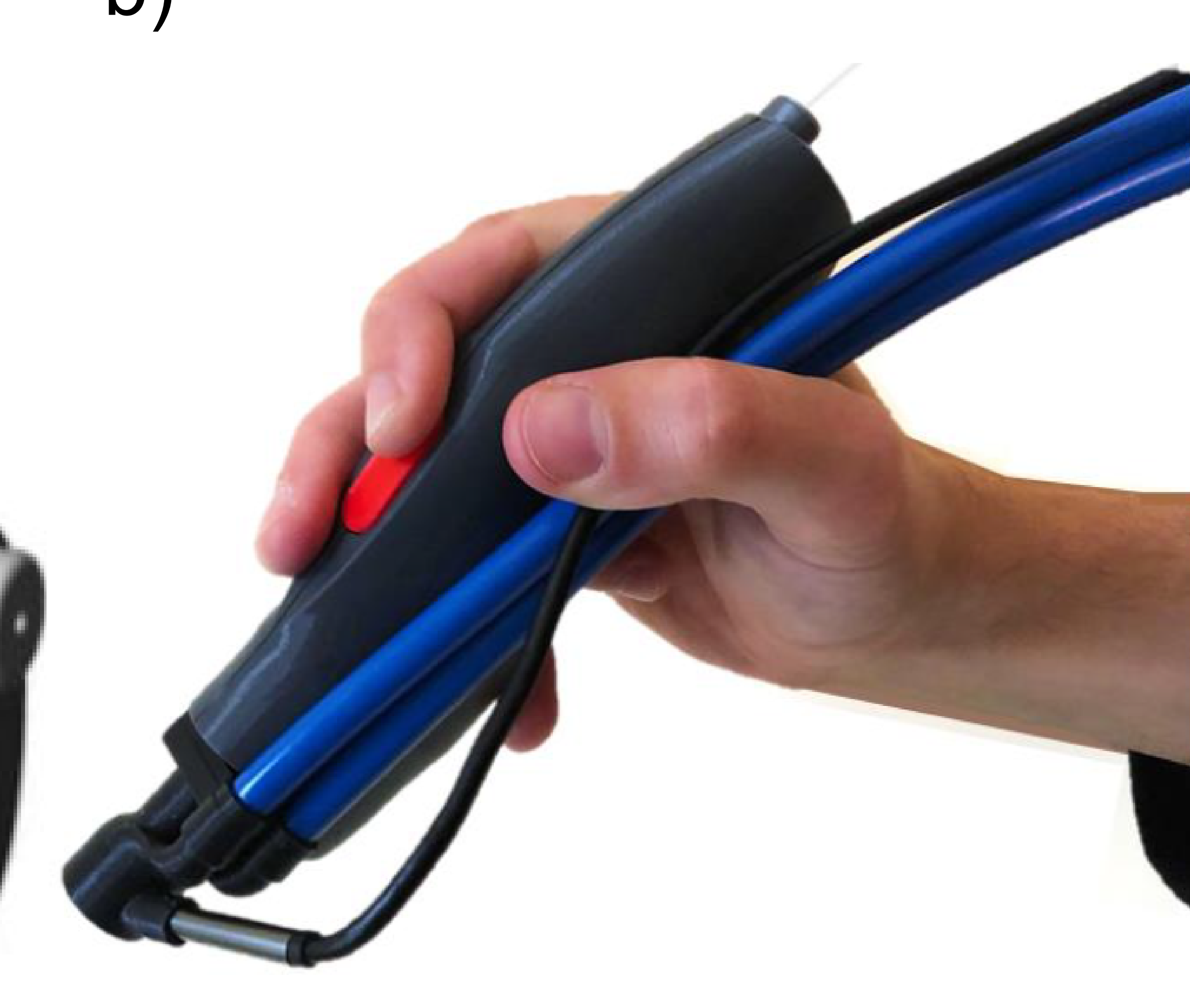

